\title{
Mobilising identity and culture in experience co-creation and venue operation
}

This paper is published as: Lugosi, P. (2014) Mobilising identity and culture in experience co-creation and venue operation. Tourism Management 40, 165-179, DOI:

10.1016/j.tourman.2013.06.005. Please consult the final published version if citing.

\author{
Peter Lugosi \\ Oxford School of Hospitality Management \\ Oxford Brookes University \\ Oxford \\ OX3 0BP \\ plugosi@brookes.ac.uk
}

\begin{abstract}
This paper examines the multiple ways in which notions of identity and associated cultural values are entangled in the management and operation of commercial hospitality spaces. The paper reviews literature on experience, identity and hospitality operations management within the experience paradigm and argues that existing work provides limited insights into how identities are 'experientialised' within hospitality venues. Empirical data are used to demonstrate how management and consumers mobilise direct and associative references to identity. The paper conceptualises the processes involved in venue operation through the notion of inducement, and it discusses the spatial, material, performative and representational practices in the creation of hospitality experiences.
\end{abstract}

\section{Keywords}

Identity; Culture; Experience; Operations management; Space; Performance; Consumption; Antipodeans; Co-creation; Event management 


\section{Introduction}

The relationship between identity and hospitality experiences is well documented. Previous work by anthropologists and geographers has examined how transactions of hospitality, involving food, drink, offers of shelter and social interaction may be used to express identity, status and power (Bell \& Valentine, 1997; Selwyn, 2000; Wilson, 2005). Research has also considered how providers in commercial contexts manipulate the servicescape and mobilise signifiers of identity and cultural values to communicate with customers, direct their behaviour and shape their consumption experiences (Lin, 2004; Lugosi, 2009; O'Mahony et al., 2006). However, this paper posits that current work examining the relationship between identity, hospitality and the management of operations offers limited understanding of how identities and associated cultural values are 'experientialised' i.e. how symbolically laden, emotionally charged, immersive, multi-sensory experiences that draw on notions of identity and culture as guiding reference points emerge or operate in venues. The paper considers social scientific literature considering the interactions of hospitality and identity, drawn from the disciplines of geography, sociology and anthropology, and literature on hospitality experience management. It is argued that the former body of work offers numerous insights into the mobilisation of cultural values and the articulation of identities within hospitality settings, but does not consider management issues. Conversely, experience management literature examines such related issues as theming, but does not provide adequate insights into how cultural values and notions of identities are incorporated into experience production.

The paper draws on empirical data to demonstrate how particular constructions of identity intersect with notions of ethnicity, nationality, gender, class and sexuality in creating hospitality experiences. It is argued that the experientialisation of identity involves the selective reconstruction and mobilisation of culturally specific expressions of values and behaviours by the operators, and it also involves consumers' performances of selves and their identification with or against particular notions of identity. It is important to stress that this paper is not concerned with hospitality and subjective experiences of identity i.e. how consumers feel about or relate to particular discourses of self. Rather, it focuses on how discourses of identity are distilled, juxtaposed and mobilised as organisational resources.

The paper's approach is broadly in the actor-network theory (ANT) tradition (Latour, 2005; Lugosi \& Erdélyi, 2009; Van der Duim et al., 2013). ANT as a methodology seeks to examine the actors, actions, processes and relationships through which things come into being (Latour, 2005). There are three principal areas of interest within this perspective relevant to the current study: first, the different human and non-human actors or actants; second, enactments i.e. how actors/actants and their networks of relationships perform knowledge and agency, resulting in particular outcomes; and enrolment, i.e. how various (human and nonhuman) actors/actants are mobilised within these enactments or performances.

This paper examines a hospitality/tourism venue/event called The Church which has been operating since 1979, and it accounts for the practices and processes through which management and consumers co-create notions of identity and culture through the experience. The paper conceptualises the processes involved in venue operation through the notion of inducement, and it discusses the spatial, material, performative and representational practices in the creation of hospitality experiences. It is argued that identifying specific practices of mobilisation within this research context helps to construct a broader thematic framework for understanding how identities may be entangled and mobilised within hospitality experiences 
in other contexts. By doing so, this paper, therefore, responds to emerging calls to examine critically the relationship between identity and spatial dimensions of hospitality (e.g. Lugosi, 2009; Lynch et al., 2011) by mapping the entanglement of material, embodied, representational and symbolic practices in the production of space. This contributes to knowledge in two key ways: firstly, it broadens our understanding of the processes through which particular spaces are created or rendered hospitable. It thus contributes to current work examining the nature of hospitality in contemporary society and how it operates in different social contexts (cf. Lugosi, 2009; Lynch et al., 2011). Secondly, it builds upon and advances our understanding of experience management (cf. Gilmore \& Pine, 2002; O'Mahony et al., 2006) by offering a context sensitive conception of the complex processes of co-creation through which hospitality experiences are constructed.

\section{Literature review}

\subsection{The experience paradigm and hospitality operations management}

Experiential consumption and its management have emerged as central themes in conceptualisations of contemporary hospitality (cf. Gilmore and Pine, 2002; Hemmington, 2007; Walls et al., 2011a). There are various debates concerning the definition of experiences, but a reoccurring set of themes are that experiential consumption is multisensory, with a significant emotional component, involving affective engagement between the consumer and organisation and between consumers (Morgan et al., 2008; Morgan et al., 2010; Walls et al., 2011a). Moreover, because such experiences are symbolically laden and thus meaningful to consumers, they are actively involved in the construction of the experience through pre-consumption desire, fantasy, anticipation, preparation as well as contribution during the experience, and remembering and storytelling afterwards (Lugosi, 2007; Morgan et al., 2010; Watson et al., 2008). Experiential consumption can also be thought of as occurring outside of, and often in contrast to, mundane, everyday experiences (Hanefors \& Mossberg, 2003), although consumer experiences are inevitably multidimensional and involve a series of functional aspects that underpin peak experiences (Quan \& Wang, 2004).

There is also a growing body of work that has explored the management of experiential consumption in hospitality (See e.g. Gibbs \& Ritchie, 2010; Gilmore \& Pine, 2002; Walls et al., 2011a). Experience management has drawn on the principles of theatre and drama (Morgan et al., 2008; Pine \& Gilmore, 1999) and is informed by Goffman's (1990) dramaturgical conception of the world. This dramaturgical perspective conceives the social world through notions of visible front stages and hidden back stages, with social actors continually engaged in micro-dramas - performing roles, following scripts and using props, with audiences receiving and responding to these performances. This approach to experience management also involves a dramatic structure or structuring, implying a journey with a beginning, middle and end, with various preconceived high/low-points facilitated by the organisation (Zomerdijk \& Voss, 2010).

A key feature in discussions of experience management that directly relates to notions of culture and identity is theming (Carbone \& Haeckel, 1994; Pine \& Gilmore, 1999; Zomerdijk $\&$ Voss, 2010). As Brown and Patterson (2000, p. 656) argued, the theming of venues attempts to 'capture the essence of a phenomenon'; in other words, it is an essentialisation of identity and cultural values. Mobilising notions of identity within theming thus reflects what Beardsworth and Bryman (1999, pp. 248-9) called 'quasification' - creating experiential 
spaces that operate 'as if they were something other', which involves borrowing various essentialised meta-narratives of identity and culture.

Organisations have been encouraged to create compelling narratives for their offerings that consumers can relate to on a personal level and in which they can immerse themselves (cf. Pine \& Gilmore, 2008; Zomerdijk \& Voss, 2010). These values are reflected in the entire organisational value-chain and are underpinned by the careful 'staging' and management of the consumer-organisation interaction (Morgan et al., 2008). The manipulation of the servicescape and the strategic use of atmospherics create 'clues' for customers that guide their expectations and perceptions, and shape their behaviours (Berry et al., 2006; Hoffman \& Turley, 2002; Zomerdijk \&Voss, 2010). Music, general noise, colours, lighting, textures, fittings, decorations, furnishing and layout influence perceptions of space and shape emotional responses; they can affect the rate of consumption, facilitate or hinder social interaction, and encourage people to engage with or reject spaces (cf. Grayson \& McNeill, 2009; Lin, 2004, 2010). This is complemented by the service staff whose aesthetic capital, emotional labour and embodied performances of self are intertwined in the experiential proposition (Gibbs \& Ritchie, 2010).

The emphasis of the experience management approach is on control and orchestration of customer experiences (Carbone \& Haeckel, 1994). It has been criticised for being superficial and excessively production centric; and subsequently, the emphasis has shifted to co-creation: the active engagement of multiple, interdependent stakeholders (consumers, managers and employees) in creating value (Chathoth et al., 2013; Morgan et al., 2010; Prahalad \& Ramaswamy, 2004; Shaw et al., 2011; Vargo et al., 2008). Co-creation relies on ongoing exchanges of information at multiple points in the organisation-consumer relationship concerning how stakeholders can develop and improve the experience through active collaboration (Lusch \& Vargo, 2006; Vargo et al., 2008). Researchers stress that, beyond information, co-creation in experiential consumption involves considerable investment and input from the consumer, for example, through the mobilisation of consumers' intellectual, physical and emotional competencies (Chathoth et al., 2013; Gibbs \& Ritchie, 2010; Lusch \& Vargo, 2006). Co-creation also involves consumers' emotional engagement with the experiential settings, and their embodied performances of self contribute to their positive experiences alongside enhancing those of others co-present (Lugosi, 2008, 2009).

There is an emerging body of work that has attempted to explore both theoretically (Gibbs \& Ritchie, 2010; Hemmington, 2007; Walls et al., 2011a) and empirically (Lugosi, 2008, 2009; Walls, et al. 2011b) the interaction of experiential consumption and experience management within hospitality. However, as it is argued in the following sections, there have been limited attempts to examine in any detail the multiple entanglements of identity within this interaction. The next section introduces contemporary conceptions of identity before reviewing work examining constructed identities, experiential consumption and the management of hospitality related experiences, specifying gaps in existing knowledge and how this study fills them.

\subsection{Conceptions of identity}

Social scientific conceptions of identity suggest that they do not exist as fixed entities and the unique property of individuals (Barth, 1969; Butler, 1999; Hall \& du Gay, 1996; Jenkins, 2004). Hall (1996), for example, has argued that it appears futile to look for some essential source of identity partly because identities do not form in isolation but also because they 
evolve over time. Articulations of selves change through engagement with a range of societal structures and agencies. In a similar vein, Bhabha $(1990,1996)$ rejected the essentialist view of self-as-identity (implying a centeredness), and replaced it with the concept of identification. The self is reliant on an other, or others, as multiple points of reference. This relationship may be one of shifting connectedness or distance and notions of self are constantly reconstructed through the interpretation, incorporation or rejection of circulating notions of identity. Consequently, identity is not treated as a fixed entity but a series of potential roles and social positions that people may adopt, adapt and experiment with in different social contexts and spaces.

In order to examine different identities or practices of identification, it is important to appreciate the interaction of spaces and embodied performances of self. Lefebvre (1991, p. 216) argued that 'organized gestures, which is to say ritualized and codified gestures, are not simply performed in 'physical' space, in the space of bodies. Bodies themselves generate spaces, which are produced by and for their gestures'. Burkitt (1999) similarly argued that the body is a critical agency in the production of our sense of selves and our social spaces. For Burkitt, the body is the site where the sensual and the cognitive intersect; consequently, embodied action is simultaneously about knowing and doing - competence and engagement, which then develops new competences. The body is caught up in complex representational practices and power relationships that transform and appropriate the meaning of human action. However, physical embodied actions create new subjective understandings as people continually engage with the human and the non-human; therefore, bodily performance reflects knowledge that produces altered versions of social spaces. Burkitt and Lefebvre's emphasis on embodied performance reflects an ecological connectedness in which place and embodied actions are inseparable. The constructions of identities are implicitly linked to the production of social space. In a reciprocal way, the production of social space shapes the nature of these performances. It is through this production of space that conceptions of gender, class, ethnicity, sexuality and nationality become entangled to produce hybridised expressions of identities.

The notion of identity as construction is useful in helping to appreciate how the cultures, values and norms linked to particular notions of identity are reconstructed as part of hospitality experiences. Identity construction is relevant to the current discussion in two ways: first, from an organisational perspective, we can consider how conceptions of identity are part of the 'propositions of hospitality' (Lugosi, 2009). Operators may draw on identity and cultural values, for example, trendiness or style (Cuthill, 2007), nationality (Brown \& Patterson, 2000) or even sexuality (Lugosi, 2009), through the management of the servicescape and human capital to differentiate their venues. Second, notions of identity also refer to consumer identities and performances of self which emerge through consumption in and of venues (Bell \& Valentine, 1997; Lugosi, 2009). In principle these two manifestations of identity in relation to hospitality can be viewed separately, although, as this study suggests, it is useful to consider how they are entangled through the production and consumption of hospitality. The next section reviews previous social scientific and management research examining hospitality and identity and outlines the gaps in current knowledge that this study seeks to address. 


\subsection{Hospitality and identity: Social scientific and managerial perspectives}

The intersection of constructed identities and hospitality experiences has been examined by sociologists, anthropologists and geographers. Studies have focused on how the construction and mobilisation of multiple expressions of identities, by both organisations and consumers, are entangled with experiential consumption. Cuthill (2007) has argued that lifestyle identities and values are symbolically reflected in various aspects of the servicescape. More specifically, in a traditional café through polished wood, golden chandeliers and 'traditional' regional food items, whereas trendy style bars use polished steel surfaces, atmospheric spot lighting, young staff wearing tight clothing and contemporary drinks offerings to reflect different identity values (Cuthill, 2007). These values are sensed and responded to by consumers who gravitate towards spaces that appeal to their notions of self. Moreover, their performances of self both reflect and reproduce those identity values, either through dignified consumption among older patrons in the case of the former venue, and through dancing, drinking and interacting among well presented young people in the latter.

In Andrews' (2005) study of holidaymakers in Magaluf, the constructions of British identities also draw upon and are reflected in material objects, behaviours as well as aural and olfactory sensations: tattooed, sunburned, often naked flesh, the smell of fried food and vomit, loud dance music, high heels, British named and themed bars, English ingredients and food thus engender the coding of space that facilitates the articulation of identities. Within such touristic production and consumption, notions of national identity intersect with those of gender and class in the construction of particular expressions of Britishness. Britishness, therefore, emerges as a polisemic, hybrid entity, in which nationality is conflated with, among other things, heteronormativity, objectified sexuality, working class culture, excessive, indulgent ingestion, conservatisms, exclusion and hostility towards foreign 'others.'

Weed's (2006) study of sports spectatorship in a drinking environment suggests that expressions of nationality emerge through singing and the celebration of contrast and conflict. Weed (2006) argues that xenophobic sentiment is not necessarily about commitment to nationalism, war or, arguably, even Britishness, but simply a momentary, carnivalesque expression of belonging in the consumption environment. Similar themes have emerged in discussions of Australian identity: the deployment of songs (Kelen, 2003) and engagement in and spectatorship of sports (Mewett, 1999) serve to construct and articulate particular notions of Australian national identity. These are utilised by and deployed within media representations (See e.g. Greiner, 2001), and, through a process of commercialisation, become entangled with other constructed identities, for example subsuming notions of New Zealand and South African identity into antipodean-ness (Crawford, 2009). These quasified notions of identity are subsequently mobilised within the experiential propositions of hospitality venues (Robinson, 2011; West, 2006).

Robinson (2011), adopting a cultural studies rather than management perspective, discusses a chain of Australian themed restaurants in the US (the Outback Steakhouse) and considers how Australian identity and culture is constructed in the organisation's commercial proposition. This chain 'indexes' and 'drags' (Rojek, 1997) a particular set of signifiers: using such objects as boomerangs, surfboards, road-signs, beer adverts, maps and flags in its design, novelty names for menu items and utilising a culturally stereotypical informal, white male character in its marketing (Robinson, 2011). Similar processes of construction are highlighted by Brown \& Patterson (2000) and Lego et al. (2002) in their discussion of Irish 
themed operations. Such theming of venues offers a safe and ludic experimentation with a hyperreal Australian or Irish culture and identity, but it is important to stress that consumers do not necessarily accept the experiential propositions offered by the venue as authentic or representative. Consumers inhabit and relate to themed venues in critical ways (See Lego et al., 2002; Muñoz et al., 2006; Muñoz \& Wood, 2009; West, 2006). Themed Irish or Australian venues can serve numerous purposes, for example, as places to relax and escape, while allowing travellers to reconnect with some aspects of their home culture. However, West (2006) suggests that such venues also act as points of departure and reflection as they help travellers redefine their identities against cultural stereotypes.

Among management researchers, Gillespie and Morrison (2001) explored how the atmospheric features of elite hotels' design reflect cultural values; and they discussed how these may be used by consumers to articulate their sense of identities. However, they did not examine in any detail the processes through which identity values are constructed or mobilised; nor were they concerned with understanding the processes of venue operation. O'Mahony et al. (2006) applied Hoffman and Turley's (2002) 'atmospherics' model in examining managerial reconstructions of national identity and culture in Irish theme bars. They discussed atmospheric elements such as the design and the inclusion of objects to convey 'Irish-ness'. They also referred to certain staff speaking with Irish accents adding authenticity to the experience, and to the friendliness of staff, which is argued to be reflective of Irish hospitableness. Their discussion of consumers point to their perceptions that Irish theme bars are inherently friendly, lively, inclusive, sociable places by the very fact that they are themed Irish. However, O'Mahony et al. (2006) did not offer any insights into how such conceptions of identity emerge over time. Moreover, it is important to be cautious in making claims concerning the inherent social properties of places. Lugosi (2009) has shown that such 'myths' surrounding a social group and their social spaces (for example friendliness or inclusiveness) may be part of the commercial proposition, and may be part of the place-myth (Shields, 1991), i.e. frequently circulating discourses about places. However, these are only reified through people's consumption experiences and in their conceptions or interpretations of those experiences, and thus they are constantly subject to contestation in specific situations.

Social scientific studies such as those conducted by Cuthill (2007), Andrews (2005) and Weed (2006) are useful for conceptualising the complex interactions between identity and hospitality experiences, although these studies did not attempt to investigate the management or operational dimensions of the consumption experience. Studies such as those of Robinson (2011), Lego et al. (2002) and West (2006) act as useful points of reference in understanding theming and consumers' reaction to representations of culture and identity; however, they offer limited insights into the broader nature of experientialisation of identity - how symbolically laden, emotionally charged, immersive, multi-sensory experiences and performances of self emerge or operate in commercial venues. Finally, management oriented studies, such as O'Mahony et al. (2006), help to appreciate how atmospheric factors, staff performances and consumers shape experiences for patrons. However, O'Mahony et al. (2006) apply an existing conceptual model to explain the broad formation of the experience rather than developing new explanatory concepts from their data. More importantly, in their study the mobilisation of identity and cultural values remains black-boxed, and it is implied that an 'Irish atmosphere' is somehow an inherent quality of Irish themed bars, at least in the perceptions of the customers in their study. This suggests there are still gaps in current knowledge concerning the processes through which norms and values associated with particular cultures and identities are entangled both in the creation and management of 
hospitality experiences. Reflecting these gaps in knowledge, this study pursued two key objectives: first, to analyse the processes through which hospitality spaces and hospitable experiences were (re)created; and second, to examine how different conceptions of identity were entangled in (i.e. how they emerge in and contribute to) this process of creation. This paper accounts for the processes through which management and consumers co-create and mobilise hybrid notions of identity and culture through the experience. It is argued that identifying specific processes of mobilisation within this research context helps to identify a broader thematic framework for understanding how identities may be entangled and mobilised within hospitality experiences in other contexts.

\section{The Study}

\subsection{Research context}

This paper focuses on a weekly social event called The Church, which was examined as part of a broader ethnographic study involving multiple hospitality sites and cases (cf. Lugosi, 2006, 2008, 2009). The Church was selected purposefully because it represented a deviant or extreme case (See Patton, 2002 for further discussion of extreme cases in purposeful sampling). As Patton (2002) argued, such extreme cases are data-rich, illuminative and relevant for addressing the research objectives - in this case to analyse the processes through which hospitality spaces and hospitable experiences were (re)created; and to examine how different conceptions of identity were entangled in this process of creation. The Church had a reputation for providing an extraordinary hospitality experience for over 30 years, which warranted further examination, and no studies had analysed it previously. Moreover, after the first visit to The Church it became clear that notions of identities were entangled in its production and consumption in multiple ways. Repeat visits thus helped to understand these entanglements in The Church, but they also provided a richer understanding of the intersections of identity and hospitality spaces in general, thus adding to the conceptualisation in the broader research endeavour.

\subsection{Data collection}

The Church part of the broader study employed two main forms of data collection: participant observation, supported by investigative research of online forums and websites. The virtual aspects of the study again utilised purposeful sampling with criteria of data richness and relevance driving the investigative process (See Lugosi et al., 2012 for further discussion of purposive sampling in such exploratory internet research). A key site was The Church's own website, which contained descriptions of the event, its history, updates on acts as well as links to a photo archive. The Church's former website also included an interactive forum. The forum provided particularly useful insights into consumer commentary about expectations and perceptions of the venue, and operational information such as the playlist of songs. Key 'streams' of information such as The Church's forum were also complemented by other sites offering commentary by consumers and cultural observers (cf. Freeborn, 2008). As Lugosi et al. (2012) argue, threads of discussion about people's experiences, short postings by consumers on internet forums, standalone journalistic pieces, images etc. treated individually offer rich but limited data; however, when utilised as a constellation of reference points this becomes a form of 'data triangulation' (Denzin, 2009, p.301), particularly as multiple sources of data were combined in this study. 
The Church was visited on nine occasions over an eleven-year period (2001-2012), with approximately 45 hours of observation ( 5 hours per visit) and data collection continued until a point of saturation was reached when no new themes were emerging from the data (cf. Strauss \& Corbin, 1998). As Thurnell-Read (2011) argued when writing about analogous consumption settings, data gathering was immersive, involving all the senses and reliant upon on sensitivity towards the embodied and emotional dimensions of the collective experience to provide rich, context-sensitive insights. Within this study, researcher engagement was closer to the observer end of the observer-participant continuum and a 'peripheral membership' role was adopted (Adler \& Adler, 1987). This involved being co-present in the venue and consuming amongst the other patrons, but I did not participate in any of the more spectacular aspects of the co-production process discussed below; nor did I wear fancy dress. I was simply one of hundreds of people in the venue engaged in vertical drinking while watching the acts on stage.

In line with other observational and ethnographic data collection endeavours (cf. Atkinson \& Hammersley, 2007), during these visits I engaged in numerous informal conversations with male and female staff and guests, and I took extensive notes during every visit that were expanded on - either on the day of the visit or the following day. Digital images and film recordings were made during two visits, which complemented the writing up process. Audio recordings of the proceedings were also made during three visits, extracts from some of which are included below.

The collection and analysis of observational data broadly followed the sequences outlined by Adler and Adler (1998). Initially, observations of The Church were general in scope and utilised ad libitum sampling ( $\mathrm{L}=$ as desired) (Lee, 2000). To paraphrase Lee (2000: 44), in ad libitum sampling, the observer notes down everything that is visible and may potentially be relevant. The study adopted a 'concurrent model of analysis' (Lofland, 2006), where analysis of relevant material was conducted during and after the fieldwork. This was important as initial observations were coded and analysed through an open coding system, which was used to identify specific, recurring themes in the data. This led to focused observation of the organisation and management of the experience, the routines of The Church, the music and the behaviours of its patrons. Finally, the study used selected observation of particular aspects of The Church and its patrons, including the dress styles, interactions between staff and guests and between guests, the security arrangements, service and product provision in terms of drinks, tickets etc., and specific songs rather than just genre, including reactions to the music. These areas were chosen because they helped to understand a) how management encouraged specific patterns of ludic consumption but also how they attempted to control patrons' behaviours; and b) how particular behaviours and embodied practices were used by patrons to express their affiliation with and difference from others.

Initial attempts to contact the venue's owner/manager for an interview were not entirely successful: he declined to be interviewed at length, saying: 'The Church does not like to publicise itself.' He was helpful enough to answer some questions about The Church's history and management. However, a subsequent attempt to contact the owner/manager was successful and the current owner participated in a recorded semi-interview lasting approximately an hour. Her responses were useful in two ways: first, and most importantly, they helped to reaffirm the credibility of existing findings; and second, they provided further details about the venue's history and its evolution. 
Data triangulation and the integration of multiple sources of data were used to establish 'credibility' and 'dependability' in the study (See Lincoln \& Guba, 1985 who use these concepts in place of validity and reliability for conceptualising quality criteria in qualitative research). For example, The Church has an online archive of photographs, dating back to the year 2000, which contained 7441 images (2000-June 2012). Analysing all the images taken between 2000 and 2010, then examining two image sets from each month from 2011-2012 was used to ensure the credibility of the findings from the observation that certain acts, activities and patterns of behaviour were a consistent feature of The Church experience. Similarly, regarding music, observation over the 11 year period revealed a particular musical repertoire and many of the same songs were played during every occasion. A posting to The Church's forum asking for a 'list of songs' played there received several different responses listing songs. Examining the different responses revealed that there were indeed numerous songs played consistently. The limited musical repertoire was also confirmed by the manageress during our interview. Considering these pieces of information together with the data gathered through participant observation helped to ensure the credibility and dependability of findings by demonstrating that repeated patterns of behaviour or activity existed, both in management and consumer practices.

Finally, the current owner/manager and her colleagues were sent a complete version of the manuscript as a form of 'member checking' (Lincoln \& Guba, 1985). Her feedback reaffirmed the study's conclusions and highlighted a number of further issues of interest. The owner/manager was also asked to provide images that would communicate to readers the people, experiences and the atmosphere of The Church. It was explained that some of the images may accompany the online version of the published article. The participant-generated visual data were a series of reflective statements made by the operators regarding The Church experience and its management (cf. Guillemin \& Drew, 2010). Consequently, these visual accounts were incorporated into the analysis. It is important to note that the images selected by the owner/manager included many of the features identified through the other methods, and thus reinforced further the credibility of existing interpretations.

\subsection{Analysis}

The data was subjected to 'thematic analysis' (Braun \& Clarke, 2006), which involved several key activities in which various data were collated, reduced and reassembled into higher order codes and then themes. The initial process of data familiarisation involved listening to audio recordings and reading and rereading the written notes produced through observations. Asking fundamental questions regarding 'who', 'what' and 'when' helped to discern configurations of operators and consumers, and recurring patterns of behaviour. Repeated reading of notes in conjunction with listening to recordings also assisted in understanding the overall structuring of the hospitality experience in terms of sequence of activities by the operators and rhythms in consumer activities. Examining the sequence of events, different actors, alongside patterns of behaviour and interaction consequently helped to identify deviations from patterns and norms that were either accepted or sanctioned.

Familiarisation led to the generation of initial codes, which broadly followed an inductive approach. However, the two objectives driving the research acted as 'sensitizing concepts' (Blumer, 1954) helping to guide the investigative and interpretative processes. The coded data were organised into themes, which were reviewed once new coded data, including images and social media postings, were added, and also re-examined in relation to other themes. This included musical repertoire, dress and body modification norms, aspects of 
operations management, including the drinks offerings, and interactions between operators and patrons and between patrons. In practice, the themes and codes most relevant to this current paper relate to the overarching dimension of 'Practices of Inducement', which was made up of four sub-themes of spatial, material, performative and representational practices. A more detailed example of the coding scheme is shown in Figure 1.

\begin{tabular}{|c|c|c|c|c|}
\hline \multirow{2}{*}{$\begin{array}{l}\text { Overarching } \\
\text { theme } \\
\text { Sub-theme }\end{array}$} & \multicolumn{4}{|c|}{$\begin{array}{l}\text { Practices of } \\
\text { inducement }\end{array}$} \\
\hline & Representational practices & Spatial practices & Material practices & Performative practices \\
\hline \multirow{7}{*}{$\begin{array}{l}\text { Primary } \\
\text { coding } \\
\text { themes } \\
\text { With reference } \\
\text { to raw data }\end{array}$} & $\begin{array}{l}\text { Internet-based ( } 0 \text { ) } \\
\text { e.g. narrating history; reproducing } \\
\text { images; providing practical } \\
\text { information }\end{array}$ & $\begin{array}{l}\text { Decoration }(0) \\
\text { e.g. minimal; flags at back of } \\
\text { stage; sawdust on floor } \\
\text { Music }(O) \\
\text { e.g. anthemic rock e.g. Bon Jovi, Living }\end{array}$ & $\begin{array}{l}\text { Drinks (types ( } 0 \text { ) } \\
\text { e.g. Fosters lager, VB (Victoria } \\
\text { Bitter); no spirits } \\
\text { Drinks (vessels) ( }(0) \\
\text { e.g. cans; plastic bottles; no glass }\end{array}$ & $\begin{array}{l}\text { Orchestration (compère) }(0) \\
\text { e.g. roll call of nations; irreverent } \\
\text { humour; swearing; ridicule; leading } \\
\text { games and competition; } \\
\text { objectification of bodies/ } \\
\text { behaviours }\end{array}$ \\
\hline & $\begin{array}{l}\text { Internet-based (C) } \\
\text { e.g. reproducing images/video; } \\
\text { posting commentary; creating } \\
\text { links on social media }\end{array}$ & $\begin{array}{l}\text { Lighting }(0) \\
\text { e.g. colourful; dance club } \\
\text { lighting }\end{array}$ & $\begin{array}{l}\text { Drinks (transaction) (O) } \\
\text { e.g. drinks tickets; cans/bottles } \\
\text { sold in a bag } \\
\text { Flags }(0)\end{array}$ & $\begin{array}{l}\text { Orchestration (security) }(0) \\
\text { e.g. giving instructions; policing } \\
\text { behaviour; ejecting unruly } \\
\text { individuals; supervising games and } \\
\text { competitions }\end{array}$ \\
\hline & $\begin{array}{l}\text { Venue-based }(\mathrm{O}) \\
\text { e.g. showing moving and still } \\
\text { images of patrons on video } \\
\text { screen; inserting humorous, } \\
\text { mocking and provocative } \\
\text { comments to still images of } \\
\text { individuals and groups }\end{array}$ & \multirow{2}{*}{$\begin{array}{l}\text { Interactive group experience ( } 0 \text { ) } \\
\text { e.g. central convergence space-dance } \\
\text { floor; standing (vertical) rather than } \\
\text { seated encouraging close physical } \\
\text { proximity } \\
\text { Spectatorship ( } 0 \text { ) } \\
\text { e.g. floor-stage; floor-screens; } \\
\text { floor-performer }\end{array}$} & $\begin{array}{l}\text { i.e. flags of Australia, New } \\
\text { Zealand and South Africa } \\
\text { Signage (O) } \\
\text { e.g. 'Church' poster at } \\
\text { entrance and back of stage; } \\
\text { signs advising customers to }\end{array}$ & \multirow{2}{*}{$\begin{array}{l}\text { Spectacular entertainment(O) } \\
\text { e.g. strip act; spectacular entertainers } \\
\text { e.g. 'human blockhead', regurgitation, } \\
\text { compere } \\
\text { Spectacular entertainment(C) } \\
\text { e.g. exposing breasts/bottom/penis; } \\
\text { lewd behaviour and participation in } \\
\text { compettions on stage }\end{array}$} \\
\hline & \multirow{4}{*}{$\begin{array}{l}\text { Internetjprinted media-based } \\
\text { (External agents) } \\
\text { e.g. journalistic commentary on } \\
\text { the Church; event listings }\end{array}$} & & $\begin{array}{l}\text { signs advising customers to } \\
\text { buy drinks tickets; directions to } \\
\text { toilets, cloakrooms }\end{array}$ & \\
\hline & & $\begin{array}{l}\text { Rules }(0) \\
\text { e.g. not throwing cans; } \\
\text { urinating only in toilets; no } \\
\text { excessively unruly behaviour; } \\
\text { no lifting people on to } \\
\text { shoulders }\end{array}$ & $\begin{array}{l}\text { Video screen }(0) \\
\text { e.g. showing particular individuals } \\
\text { and groups; projecting adverts and } \\
\text { instructions to patrons } \\
\text { Dress }(0) \\
\text { e.g. staff T-shirt with Church }\end{array}$ & $\begin{array}{l}\text { compettions on stage } \\
\text { Musical appreciation (C) } \\
\text { e.g. singing; knowing song lyrics, } \\
\text { including national anthems } \\
\text { Co-preparation(C) }\end{array}$ \\
\hline & & \multirow{2}{*}{$\begin{array}{l}\text { Temporal distinction (0) } \\
\text { e.g. Sundays only; every } \\
\text { Sunday; } 1-4 \mathrm{pm} \text { only }\end{array}$} & $\begin{array}{l}\text { 'rule' printed on back } \\
\text { Dress (C) }\end{array}$ & $\begin{array}{l}\text { e.g. creating fancy dress; dressing } \\
\text { up; 'making' up; attending together }\end{array}$ \\
\hline & & & $\begin{array}{l}\text { e.g. fancy dress; informal sportswear, } \\
\text { revealing party wear; thongs; national } \\
\text { colours (rugby tops) } \\
\text { Props (C) } \\
\text { e.g. wigs, plastic guns and swords, } \\
\text { wands, inflatables, fake glasses, mock- } \\
\text { ears; badges } \\
\text { Make-up(C) } \\
\text { e.g. national flags painted on faces; } \\
\text { make-up to complement fancy-dress; } \\
\text { words and slogans written on face/body }\end{array}$ & $\begin{array}{l}\text { Drinking (C) } \\
\text { Interaction (group-individual) (C) } \\
\text { e.g. cheering when women } \\
\text { exposed themselves; booing if } \\
\text { they didn't } \\
\text { Interaction (individual- } \\
\text { individual/group; group-group) } \\
\text { (C) } \\
\text { e.g. talking; dancing; singing } \\
\text { together; flirting; kissing; } \\
\text { touching; taking photos; } \\
\text { cheering/booing during roll call of } \\
\text { nations }\end{array}$ \\
\hline
\end{tabular}

Figure 1. Coding scheme

It is important to account reflexively for the researcher's role and positionality in both data gathering and analysis (See Limb \& Dyer, 2001 for further discussion of reflexivity and positionality in qualitative research). Being a white, heterosexual, physically mobile, middleclass, male researcher whose national identity is foreign to British and antipodeans provided a series of opportunities and challenges during the research process. I could easily 'fit' into the social context and participate in the consumption context to gain rich, embodied, contextsensitive, first-hand insights into the broad experience offered by The Church. The visible nature of The Church and the behaviour of its staff and consumers also enabled me to gain a detailed understanding of the practices involved in its operation. Being a foreigner may have distanced me from being able to feel as a 'true insider' the sense of national identity experienced by patrons from Australia, New Zealand, South Africa or the UK; although the notion of true insider is problematic because it suggests a particular, unified, stable identity experienced by everyone from a culture, which has been brought into question by numerous writers (See Hall \& du Gay, 1996). My sense of 'difference' or 'outside-ness' was also reinforced by my values and principles. I have conducted research with gay and lesbian 
consumers, as well as heterosexual women, attempting to uncover the complex and often asymmetric power relationships that influence their experiences of culture, identity and spaces. My moral and ethical values, which underpinned my research, frequently contrasted the values entangled in The Church's practices. Such contrast and difference in terms of positionality helped to reinforce a necessary sense of 'anthropological strangeness' (cf. Agar, 1996) and thus helped me to examine critically The Church's practices differently than if I was immersed in the experience as a total participant. Moreover, I attempted to generate a rich, detailed description and a transparent interpretation of The Church's practices, based on the evidence from different data sources, to provide readers with a nuanced insight into both the experience and the operation.

\section{Findings}

\subsection{The Church}

According to its operators, the Church began in 1979 in a London Pub and from the beginning attracted Australians and New Zealanders who wanted meet regularly; so historically, the essence of The Church already drew on notions of common national identity (See e.g. The Church, 2012). In marketing material, The Church's operators previously employed religious language in their construction of their hospitality proposition - referring to the customers as 'congregation' and the 'faithful flock', to the rituals of consumptions as 'the order of service' and to its founder, Sean Sullivan, as the 'High Priest' (The Church, 2008). They also invoked notions of religious pilgrimage in stating that a visit to The Church was 'A 'must do' on any OE [Overseas Experience] list' (The Church, 2012). However, it is important to stress that the religious references were used playfully to reinforce the ludic, transgressive nature of the experience. For example, they stated that 'the principle that people cannot be forgiven unless they have sinned is upheld every Sunday' (The Church, 2008). Furthermore, a joke retold by several of the comperes is that when phoning home to relatives 'down under', people could proudly tell them that they spent Sunday in 'the church' (suggesting religious observance). The Church's experiential proposition thus employed a symbolic inversion of the church as a social institution, steeped in ritual and serving a community of individuals seeking a collective experience.

Since its inception, The Church has moved around nine venues in London; however, there are nine distinct features of its overall format, operation and the experience it offers that have remained consistent. One, it is important to stress that The Church only opened on Sundays between $12 \mathrm{pm}$ until $4 \mathrm{pm}$, hence the religious reference above. Two, the emphasis was on vertical drinking, with patrons compacted into single principal space, where the acts and games took place on a stage. Three, the decoration was minimal, with a sign hung on the back of the stage which read "The Church", which was accompanied by the flags of Australia, New Zealand and sometimes South Africa, and the lighting was that of a night-time dance venue.

Four, loud music was played and The Church's musical repertoire was relatively consistent, and a similar set of songs were usually played every week. The music was oriented towards anthemic rock and uplifting popular music. This included songs such as: Reef Place your hands; Guns N' Roses Sweet child o' mine; AC/DC You shook me all night long; Jet Are you gonna be my girl; Van Morrison Brown eyed girl; Neil Diamond Sweet Caroline; Proclaimers I would walk 500 miles and Brian Adams Summer of 69, which featured regularly, and the audience reacted positively to these songs. People often knew the words to many of the songs 
and frequently sang along enthusiastically. During previous visits when the Australian anthem was played, large sections of the room cheered and started to sing, while others booed loudly.

Five, drinks could be purchased by obtaining a ticket, which could be exchanged for three canned or bottled drinks, sold in clear plastic bags. However, it also became possible to buy drinks individually at the bar. A narrow selection of drinks was available to customers, which included cider and beer, with Australian brands consistently being part of the offering (e.g. Fosters, Tooheys and VB). In previous years alcoholic lemonade was poured from glass bottles into plastic cups, but this was replaced over time by a choice of alco-pops sold in cans, and more recently by alco-pops in plastic bottles. Water and soft drinks were available but spirits, when sold, were only available as part of pre-mixed cans.

Six, The Church was hosted by a compère with different men performing the role. The compère told explicit, politically incorrect jokes, introduced the acts, judged the competitions and, depending on who was assuming the role, sang songs. Another important ritual which was performed by every compère was the roll call of nations. He asked those present whether there were Australians and New Zealanders there; and, depending on the person, he also asked whether people from other nations, such as South Africa, England, Wales and Scotland, were there. This resulted in loud cheers from the people from those nations and boos from people of other nationalities. This was a useful way to gather information about the nations that were represented on any day.

Seven, there were a number of weekly acts, including female and male strip performances. Other acts included a man who swallowed snooker balls and goldfish, and then regurgitated the objects in a specific order. Games were also played every week. These included musical chairs, limbo and spinning with a stick and seeing if a person could then step over the stick successfully. One of the consistent rituals was the 'boat race': a drinking game where teams of four competed to see who could drink cans of drink quickest. Another feature in previous years was a competition to see who would do the most outrageous thing on stage. This usually involved stripping or some self-exposure. The other regular practice was at the end, when women from the audience danced on stage and often exposed their breasts to the audience.

Eight, there were a number of set rules and not throwing cans was one emphasised by most of the compères. It was also stated on the back of The Church wardens' t-shirts. Other important rules were that people could not climb on to other people's shoulders and people could not pick up or lift others. Throwing cans, spraying or splashing drinks, excessively rowdy behaviour resulted in warnings from security staff, and urinating anywhere other than the toilets were grounds for immediate expulsion.

Nine, linked to the previous point, large security men were stationed all around the venue. Several stood on the stage to stop people from getting up during the acts; whilst others stood at the sides and the corners watching the crowd from elevated positions. Unruly individuals were usually cautioned by the security men first and forcefully expelled if they persisted.

Some aspects of The Church have changed. For example, the boat race used to involve cans of beer but more recently the operators have moved to using either soft drinks or nonalcoholic beer. In previous incarnations of The Church, sawdust was placed on the entire floor of the venue to prevent slippages, but when it moved in 2003 the operators of the new 
venue did not allow them to continue to use sawdust. In recent iterations of The Church, the organisers also used technology to enhance the experience. They filmed patrons from an elevated position and projected moving and still images of people on to a screen, which was watched by the other consumers. Images of people were often accompanied by commentary. For example, in one incident they pointed to a woman with a low cut dress and enclosed the caption: 'Cheer if you want to see her boobs'. This received a large 'cheer' from the audience, which turned to 'boos' when the woman continued to remain clothed. This was followed by another caption: 'If the goods aren't for sale, don't put them in the shop window'. This form of representation continued throughout the afternoon, with men and women being subjected to scrutiny and commentary, with captions making irreverent commentary on sexuality, ethnicity, clothing, physical attributes and behaviour. However, these represent incremental adjustments to its organisation, and overall The Church experience has remained consistent.

In the remaining part of this paper an account of one visit to The Church is provided. The emergent themes from this and other visits are then discussed in the subsequent part, before some general conclusions are drawn and implications for management and further research are outlined. The inclusion of an account of one day rather than extracts from several different visits is necessary for several reasons. First, as the data suggest, the format of The Church has remained largely unchanged: so the moral tone, behaviours, activities and their sequences on this day closely matched those of every other day. Second, presenting a detailed description of one day, in its entirety, and in its temporal sequence, enables the reader to appreciate both the overall experience and the specific factors (including the actors, spatial relations, objects and embodied practices) that collectively make up that experience. Finally, it is important to warn readers regarding the explicit content of the account, which may cause offense. Bowman (1989) and Andrews (2009) included in their work graphic language and descriptions of sexist and sexual behaviour to help readers appreciate the identity performances, power relations and tensions in their fieldwork settings. Similarly, unedited extracts from The Church have been included here to demonstrate how transgressive behaviours and attitudes related to gender, ethnicity, sexuality, race and morality were deliberately mobilised in the construction of the experience.

\subsection{The Church experience}

\section{Sunday 11.30 a.m., London}

Turning into the estate complex, we arrived at the end of a 500-strong queue, with more arriving all the time behind us. Most people were working their way through their beers talking to people in front and behind them. ${ }^{1}$ Several large security guards were walking up and down the line selling drink tickets [that could then be exchanged for drinks at one of the bars]. Getting to the end of the queue, the drinking got faster as the men and women got rid of their drinks; several large bins next to the queue were overflowing with empty cans.

As we got to the door, we were told assertively to take off our coats and hand them into the cloakroom before being ushered upstairs to pay the entrance fee. As we came up the stairs, we were hit by the overpowering stagnant aroma of fried

\footnotetext{
${ }^{1}$ Recent concerns about alcohol and public disorder have led to a ban on drinking in the street and patrons approaching the venue were instructed by The Church wardens to dispose of their alcohol. The security staff also confiscated drinks from people as they left the venue.
} 
meat and onions that had impregnated every inch of the room. Despite the early hour, people were already queuing up to buy the dubious looking hot-dogs and hamburgers.

We made our way through some doors into a large hot and crowded space where several hundred people were crammed in tightly. The only other notable decorations were the national flags of Australia, New Zealand, Ireland and South Africa, hung at the back of the stage, and a large sign that read 'The Church' above the stage.

The crowd was about 70 percent male, 95 percent white, and at a guess, 98 percent of the people were under 35 . The majority of the people seemed to be in their 20s. Groups of people were dancing around with men and women mingling in the crowd. On this day, as always, there were several groups of men from rugby teams wearing their team's colours. One group of men were dressed in 70's outfits wearing wigs, false moustaches and sunglasses, while two other men were wearing Santa Claus outfits. I even saw several men wearing tuxedoes who looked like they had been to a party the night before and came straight here afterwards. [...]

\subsection{0 p.m.}

The compère finally came on stage. This week a man named 'Fat-Bloke' was the master of ceremony. He came to the front of the stage and stripped off a few layers of clothing to reveal a skin-tight, white, star-patterned body-hugger, with tassels on the arms. He 'mooned' the audience and sang two songs. During one song, 'I would do anything for love' by Meatloaf, when it came to the chorus, instead of the words 'no I won't do that', he sang 'no I won't fuck that', whilst pointing to someone in the crowd. During the next chorus, he held the microphone out to the room and the crowd enthusiastically joined in singing.

As with all the compères, 'Fat-Bloke' shouted 'do we have any Australians in today?' Half the room cheered while the other half booed. He then asked whether there were any people from New Zealand, and this time the other half of the crowd cheered while the first half booed. This was done for the South Africans, Irish, Scottish, and English. In between two countries, people started to boo and he reprimanded them by saying 'I haven't given anyone permission to boo!' The crowd fell silent. He then asked whether there were any Americans there. Three or four people cheered and the rest booed. 'Fat-Bloke' then asked if there were any French there and everyone seemed to boo. He then asked if there were any men there, women there, and surprisingly, any 'poofs' [homosexuals] there. Even more surprisingly, this still got a cheer.

$[\ldots]$

Someone shouted something at him from the audience and his retort was 'don't heckle me I am a professional, just like your sister!' He went on to say, that he was told he could not tell racist jokes, and then proceeded to tell the following joke:

'There were two Belgians called 'Paddy' and 'O'Keefe' [everybody laughed]. They both go to hospital with their ears burnt. The doctor asks 
one of them how it happened. Paddy replies 'I was ironing when the phone rang [he simulated the man putting the iron to his ear].' The doctor asks how second man was burned. Paddy says 'he phoned the ambulance for me."

He went on to make jokes about people from South Africa and commented that they must be surprised to see 'blacks' and 'whites' peacefully enjoying themselves under the same roof. He told a joke about every nation that was present, and then encouraged the crowd to chant 'who ate all the pies' at him. His act finished with a 'prayer', where he thanked God for beer and reminded us that we should keep our cans in our hands.

[...]

The female stripper came on stage; there was a huge cheer from the crowd and most of the women flocked to the toilet, while the men stood and faced the stage. [I often used these opportunities to speak to women who went outside to the courtyard.] A member of the audience was brought on stage and she proceeded to squirt whipped cream over her breasts. [...] As soon as the routine ended there was a massive exodus by the men to the toilets.

$[\ldots]$

The male stripper came on stage; there was a loud cheer from the women in the crowd, which was then partially drowned out by booing from the men. There was another mass exodus by the men towards the toilets while the women faced the stage.

[...]

Six women took part in the first round of the wet T-shirt competition. After introducing themselves, the compère poured water over the women before turning to the crowd and asking who they thought the winners were. The women from New Zealand and Australia took their T-shirts off straight away and the crowd cheered. The compère turned back to one of the women still wearing her top and shouted 'do you think she's done enough?' The crowd screamed back 'noooo!!!!!' He then said 'do you think she should take her top off?' The crowd went wild.

$[\ldots]$

There was a competition among the men to see who could do the wildest thing on stage. Out of the five men taking part, three immediately took off all their clothes and danced around the stage naked. There was a mixture of boos and cheers.

[...]

The compère came to the front of the stage again to end the week's celebrations. He reminded everyone about going to the [Australian theme bar] Backpackers afterwards, before calling the women only to come up on the stage. [...] Within five minutes, four women were dancing on stage with the braver ones putting on a more elaborate show for the audience. [...] One girl walked to the front of the stage, lifted her top half way up in a provocative way, and gave the room a sultry look as if to say 'should I?' The crowd went wild. [...]

\section{Analysis and discussion}

The Church was a carefully managed, orgiastic form of hospitality and the experience was linked to specific (re)constructions of antipodean identity and culture, which were distilled and mobilised, by both the organisers and consumer, in several ways. Direct references to 
antipodean identity and culture included making explicit reference to Australians or New Zealanders in the roll call of nations, in the description of The Church and its history on its website, and in the display of the nations' flags in the venue. Associative references are those attitudes, values and behaviours stereotypically associated with Australians; and, to some extent, New Zealanders (cf. Crawford, 2009; Fiske et al., 1987), i.e. masculine, heterocentric, informal and 'easy going', valorising 'mate'-ship and enjoy drinking, sports and competitive play. Many of these themes, for example, masculinity, low-hierarchy, the importance of sport, 'mate'-ship and even enjoyment of beer, re-emerge in empirical studies of Australian and New Zealand identity and culture (cf. Hofstede et al., 2010; Phillips \& Smith, 2000; Purdie \& Craven, 2006), and in studies of popular culture associated with Australians (Greiner, 2001; Mewet, 1999; Robinson, 2011). However, it is important to note that national identities and cultures are complex constructions, influenced by such issues as gender, age and class, and constantly open to contestation. Therefore, it is not suggested here that such attitudes, values and beliefs were 'real' or representative of antipodeans; they were merely repeated (re)constructions, produced through ongoing processes of 'quasification' (Beardsworth \& Bryman, 1999).

Within The Church, the operation of quasification can be understood through the notion of 'event dramaturgy' (Ziakas \& Costa, 2012). Event dramaturgy encourages researchers to consider how a social or cultural group attempts to articulate through 'projection and/or performance' - the staging of social dramas and enactment of rituals - various symbolic interpretations about the values and social order associated with the group (Ziakas and Costa, 2012, p.32). Consequently, notions of quasification and event dramaturgy help us appreciate what happens in experience creation; the challenge is to examine how this happens in practice i.e. to understand the interactions of processes, actions and actors in the construction of experience, and to interrogate how notions of identity and culture are entangled. Moreover, while notions of dramaturgy help to interpret the symbolic dimensions and meanings of experience, it is also useful to think more broadly about other aspects of event construction, which do not necessarily operate symbolically, but contribute to the experience.

Within The Church, 'antipodean-ness' was not a singular identity, but emerged as a variety of values, attitudes, roles, characters and behaviours to be created and consumed. Notions of antipodean origin were entangled with gendered, classed and sexualised expressions of self, and the experiential proposition utilised hybridised notions to antipodean-ness to elicit particular subjective experiences of space. Analogous to Louis Althusser's (1984) notion of ideological 'interpellation,' the production and organisation of space in The Church called out to, or 'hailed,' consumers - prompting them to engage with the experience in particular ways. Consumers were expected to recognise and respond appropriately to these conceptions of antipodean identity as they (re)created the experience.

Direct and associative references to antipodean identity were mobilised in conjunction in the venue's place-image and place-myth (Shields, 1991), its operation and in the consumption experiences it offers. A key concern here is how these expressions of antipodean identities emerged and were mobilised. It is important to stress that The Church was not a singular place to be occupied but an experiential space reproduced in various locations. Therefore, it is useful to think of its (re)construction as inducement - a process through which conceptions of identity, (sub)cultural values and beliefs, and expressive behaviours were brought together in the recreation of experiential space. 
Inducement involves the continual mobilisation of labour and capital, the manipulation of the servicescape, juxtapositioning of objects and sounds, representational acts and embodied performances of selves that perpetuate experiential possibilities. In other words, the combination of these elements makes it possible, though does not guarantee, that specific hedonic experiences are accessible. It is important to stress that inducement should not be thought of as a purely managerial exercise; rather it is a process where the commercial operators construct 'propositions of hospitality' (Lugosi, 2009), partly through the 'indexing' and 'dragging' of cultural references (Rojek, 1997), and the creation of 'clues' for the consumer (Berry et al., 2006), which are received, interpreted, resisted and realised by consumers. The hospitality offering and the subjective experiences of hospitality are cocreated by the operators, consumers and other agencies that either regulate these spaces or create representations of them.

Inducement and the production and consumption of the hospitality experience can thus be thought of as 'practices of mobilisation'. The following sections elaborate on this notion by discussing four dimensions: spatial, material, performative and representational practices. Some of the issues discussed within spatial and material practices have been conceptualised within work on servicescapes and atmospherics. For example, Bitner (1992) distinguished between: 'ambient conditions' such as noise and music; 'space/function', including layout, furnishings etc.; and 'signs, symbols and artefacts' such as signage, personal artefacts and style of décor, grouping them under environmental conditions. Others such as Hoffman and Turley (2002) categorised design, furnishing, layout, music, lighting etc. under 'inanimate environment' factors. Consequently the discussion of The Church draws on this literature in its analysis.

The areas addressed under performative practices, among operators, staff and consumers, have received much less attention. The roles of staff and consumers in contributing to service experiences have been considered in the services marketing/management literature (See e.g. Tombs \& McColl-Kennedy, 2003; Zhang et al., 2010; Zomerdijk \& Voss, 2010). Hoffman and Turley (2002) identified 'contact personnel' factors (including appearance and gender), and pointed to 'other customers' as a third category of enquiry, although their analysis focused on the role of crowding. More recently, Grayson and McNeill (2009), taking a more distinct hospitality focus, discussed under 'social factors' such issues as customer types, number and appearance alongside personnel, including their appearance and uniforms. However, such conceptualisations of staff and customer roles draw on services management perspectives rather than adopting a broader social science approach in attempting to understand the practices and processes involved in their behaviour in an experiential setting. Moreover, in this body of work the issues surrounding identity highlighted in this paper remain under-examined.

Finally, it is useful to stress that, although some spatial, material, performative and representational practices have corresponding conceptualisations and associated areas of debate in existing literature, the practices discussed under the four headings below frequently cut across the categories adopted by other authors examining servicescapes/atmospherics. The current analytical framework also introduces issues not addressed in previous works. For example, it is interesting to note that Berry et al. (2006), like Hoffman and Turley (2002) discuss staff behaviour and appearance (i.e. their uniforms) under one theme: humanic clues. In contrast, this paper makes a clearer distinction between staff behaviours, which are considered within performative practices, and the material practices involving uniforms and clothing in general among staff and patrons. Developing a cross-theme approach, therefore, 
offers an alternative conceptualisation of the experience construction process rather than simply and uncritically importing conceptual frameworks from other disciplines.

\subsection{Spatial practices}

Spatial practices refer to the way space is organised; and, more importantly, to the processes that shape people's interaction with and in that space. In this case, they refer principally to organisational attempts to shape the experience, and include the manipulation of the servicescape and the strategic management of atmospherics (cf. Grayson \& McNeill, 2009; Lin, 2004, 2010). Within The Church there was minimal decoration and the emphasis of the layout was on facilitating a collective experience. Large numbers of people were compacted into an open space, where vertical drinking and close spatial proximity encouraged mutual awareness and interaction. Previous research, which often focused on retail rather than hospitality, pointed to the negative effects of crowding (cf. Grayson \& McNeill, 2009; Machleit et al., 2000). However, studies have pointed to the importance of 'social density' in generating a positive atmosphere, particularly in group-oriented consumption experiences, which would be undermined by social segregation (See Tombs \& McColl, 2003). Social density may not only increase mutual awareness and the adoption of behaviours and emotions (contagion), but can also lead to an intensification of experience (increased arousal) (Freedman \& Perlick, 1979). The Church case reinforces how encouraging what we may call 'positive crowding' may be useful in an operational context where social density is so fundamental to the overall experiential proposition.

In addition to facilitating positive crowding, there are various practices used to 'intensify' the experience. The Church's management played energetic and uplifting types of music, loudly to create a ludic atmosphere and intensify physical movement, which, as Jacob (2006) and Milliman (1986) argued, also increased the rate of consumption. Music-facilitated increases in the rate of consumption may be caused by noise levels reducing opportunities for meaningful conversation and drinking being a substitute activity. Increased drinking may also be explained by 'arousal', insofar as environmental stimuli may lead to psychological effects such as changes in perceptions in time and physiological effects such as raised blood pressure or cardiac frequency (See Forsyth \& Coonan, 2008 and Guéguen et al., 2008 for further examination of arousal and the relationship between music and social drinking). However, it may be a combination of these factors, coupled with social norms and people conforming to the drinking rates of those in their company (Aitken, 1985). This intensification and elevation of the consumer experience was reinforced by the colourful, club lighting. The effect of light as a means of influencing perceptions, stimulating emotional responses and directing behaviours has been explored in hospitality settings: dim lighting has been associated with comfort, while bright lights with arousal (See e.g. Lin, 2004; Countryman \& Jang, 2006). Within this type of experiential context, the contrast of dim ambient lighting with bright, colourful night-club style illumination seeks to stimulate arousal, leading to various cognitive, emotional and physiological responses (Guéguen et al., 2008). The establishment of a principal gathering area (the dance floor) and the organisation of the activities on stage and on the projected screen also reinforced the importance of spectatorship i.e. floor-stage and floor-video screen relations within the environment.

These spatial practices of intensification utilised 'sensory design' (Zomerdijk \& Voss, 2010) - the manipulation of several environmental factors to stimulate multiple senses - which seek to provoke cognitive, emotional and physiological responses (Bitner, 1992). Such spatial practices, involving sensory design, stress what Zomerdijk and Voss (2010) call the 'dramatic 
structure'. Dramatic structure refers to the design of the consumption experiences to help consumers to adopt an appropriate mood, frame of mind; and, subsequently, behaviour. This also involves the sequencing of particular moments and events, within the overall experience, which have peak elements, creating emotional climaxes. These aspects of sensory stimulation and dramatic design were enacted and reinforced through multiple performative and representational practices, which are discussed below.

Spatial practices and attempts at intensification also included the rules that govern behaviour. As Goffman's (1990) work suggests, all social contexts have associated rules and role expectations. However, The Church has specific, explicit rules, which, rather than directly exclude drunkenness and revelry, prescribe both the limits of revelry and how drunkenness can be experienced in space. This includes not throwing cans, bottles or liquids, multiple people not holding on to each other and jumping around while dancing, or lifting people on to shoulders. It is important to stress that rules within spatial practices only refer to what people can or cannot do; how these rules are communicated and enforced will be discussed in the remaining sections.

Finally, it is also useful to stress the importance of the temporal dimensions as particular aspects of spatial practices. Organising The Church once a week, on Sundays, in a compressed period of time during the day $(12 \mathrm{pm}-4 \mathrm{pm})$ reinforced that this was a temporary space/time. Time compression undoubtedly facilitated accelerated alcohol consumption. Moreover, from an event dramaturgical perspective, temporal distinction and compression also reinforced that a liminoid experience (Turner, 1982), involving intensive, transgressive hedonistic consumption, was part of the experiential proposition. Temporal distinction, along with the rules and the organisation of the servicescape discussed above may not have referenced antipodean identity directly; rather, it made associative references to antipodeanness highlighted above (cf. Crawford, 2009; Fiske et al., 1987; Greiner, 2001; Mewet, 1999). By doing so, it also helped to give shape to the overall experiential context in which more direct references to antipodean identities were mobilised.

\subsection{Material practices}

Material practices refer to the specific use and mobilisation of physical objects within the production and consumption of the experience, and they include organisational and consumer practices. Some of these 'explicit communicators' (Bitner, 1992) were largely functional facilitating the overall experience, for example, the signs advising people to buy drinks tickets, pointing to the toilets, or the large video screen which showed images of other revellers, adverts and instructions for patrons. Other explicit communicators such as the Australian and New Zealand flags made direct and explicit reference to the antipodean identities entangled in the Church experience. This entanglement was also reflected in the sale of Australian brands of beer or bitter. The Church's owner said they used to buy Australian brands as a way to offer a 'taste of home' for Australian customers, and The Church are now approached by distributors of Australian brands, who associate the event with Australians. The national flags and Australian branded drinks were thus mobilised as 'symbolic artefacts' in environment and experience management, used to reinforce associations between nationality, culture and space (See Bitner, 1992 for a more general examination of signs and symbols in the management of the servicescape and Clarke et al., 1998 for discussion of signs and symbolism deployed in pub environments to signify cultural values). 
Some objects may have broader implications for the service experience and may reflect the associative references to antipodean identities referred to previously. In The Church, there was a limited choice of drinks sold, in cans or plastic bottles, in threes, in plastic bags. As noted previously, drinks could be bought individually, but emphasis was placed on purchasing tickets, with which three drinks could be obtained. The material aspects of drinks and their distribution may have helped efficiency by reducing operational complexity; cans and plastic bottles also minimized the risk of injury caused by glass. However, the materiality of drinks arguably also reflected informality (i.e., drinking from cans and carrying cans in bags) and emphasised intensive alcohol consumption (purchasing three at a time). The manageress also added that purchasing three at a time facilitated buying 'rounds' of drinks, thus emphasising the social aspect of consumption. Drinks thus acted as mechanical clues (Berry et al., 2006), shaping consumer perceptions and expectations of The Church as a particular type of unpretentious, ludic space alongside shaping their consumption behaviours. Again, these may not be direct or even intentional references to antipodean identities and cultural values - although they appear to reflect associative references to them.

Dress was an important material aspect of the experience. Security staff wore white t-shirts carrying the Church logo on the front and the following inscription on the back: 'KEEP "CHURCH” COOL, LET IT BE THE RULE, HOLD YOUR CAN, DON'T BE BANNED.' The t-shirts distinguished staff, although this 'uniform' was still informal, in line with the rest of the experiential proposition. The t-shirts also acted as functional clues (Berry et al., 2006) allowing the organisation to communicate explicitly and reinforce the rules governing participation. As noted previously, Berry et al. (2006) considered issues of clothing as humanic rather than functional clues, although they acknowledged the close interaction of the two types of clues. More importantly, they focused on staff appearance, reflecting again the production bias of their perspective. Drawing on the principles of co-creation, it is important to consider clothing, associated props and make-up among consumers as being central to constructing the experience. Some aspects of dress, props and make-up again made direct reference to antipodean identity, for example, clothing with the colours of national teams, flags of Australia and New Zealand (draped over people's shoulders), fancy dress jars of Vegemite - an Australian sandwich spread, or having national flags painted on various parts of bodies.

Other aspects of clothing celebrated the cultural values, associated with antipodean identity, that were central to the Church experience. This included informal clothing e.g. t-shirts, jeans, combat trousers etc., reflecting low-hierarchy, although some women dressed for a party, wearing designer skirts, dresses and tops. Fancy dress was also prominent, whether referencing TV and films e.g. Dodgeball, Where's Wally, Thunderbirds etc., or types of occupation e.g. lifeguards, nuns, pilots etc., or just utilising an eclectic mix of colourful clothes, wigs, fake moustaches and other accessories. In all cases, fancy dress, make-up and props reflected an active engagement with, celebration of, and contribution to, the hedonistic aspect of the experience.

\subsection{Performative practices}

Performative practices refer to the embodied acts, including physical actions, gestures, and verbal and non-verbal communications. The gendered and sexualised consuming body was central to processes of inducement: the ingestion of alcohol, singing, dancing, cheering, booing, self-exposure, kissing, touching and even taking photos embodied the cultural values associated with social space. The body was at once the physical site where consumption 
occurred, while the objectified body was used in the construction of the overall experience. On the organisational side, it is important to highlight the humanic clues (Berry et al., 2006) involved in orchestration, as performed by the security guards and the compère. The security guards provided instructions, and their surveillance was visible, which also acted as functional clues (Berry et al., 2006) reflecting the ordered nature of experience. More importantly, orchestration by the security was often physical, involving the pushing and pulling of bodies, and ejecting people when necessary. The compère also had several important roles in orchestration and inducement. First, swearing, risqué jokes, ridicule (both of himself and consumers), and the objectification of male and female bodies reinforced the moral script for the consumption experience. The compère's orchestration perpetuated the notion that this was a liminoid space, where existing moral norms were subject to inversion. No doubt, many people engaged in these behaviours outside of this space, but here, as in Andrews' $(2005 ; 2009)$ contexts, playful deviance was not only legitimised but celebrated. Drawing on Zomerdijk and Voss' (2010) parlance, this orchestration reflects attempts to emotionally engage consumers while reinforcing the dramatic structuring of the experiences by emphasising through norm-breaking distinct emotive peaks.

Second, and also reflecting the desire to engage consumers and stress dramatic peaks (Zomerdijk \& Voss, 2010), the compères lead the games and prescribed the behaviour for participants, for example, encouraging participating men and women to expose themselves and to compete against each other. Orchestrating these activities utilised associate references to antipodean attitudes and values by a) reproducing and celebrating masculine competition, b) referencing working class values and norms, and c) reinforcing particular gender roles, for example, women as sexual objects. Moreover, these games were tied explicitly to national and gendered identities as teams from different nations and men and women competed against each other. These activities, again, could be understood to be groups making a series of 'symbolic statements' (cf. Handelman, 1998; Ziakas \& Costas, 2012) about their cultural values and identities, but the games also directly added to the intensification of the collective experience.

Finally, the compère mobilised the notion of collective identity through his roll call of nations, which encouraged people from specific nations to produce their own space. In line with Hall's (1996), Bhabha's (1996) and Barth's (1969) assertions, notions of the other were used by the compère to create and emphasise social cohesion. Showing solidarity and affiliation toward one type of person relied on visible dissent toward others. By appealing to specific common themes, mainly around nationality, gender and sexuality, the compère rallied certain members of the crowd. The production of hospitality space was therefore tied to asymmetric power relations, which relied on the domination by certain factions of others and was dependant upon their ability to project influence and their identities over space. As Barth (1969), Weed (2006) and others argued, conceptions of identities emerged or were mobilised through assertions of power, contrast and conflict with other national and sexual identities. This did not establish an alternative singular, fixed notion of identity; rather, following Barth (1969) and Weed (2006), we can only talk about expressions of identities as they became manifested through these struggles to assert power over space. The strategic mobilisation of these expressive identities, through the process of orchestration, was used to regulate the crowd and to reinforce certain patterns of behaviour in would-be participants. However, these expressions of identity, inclusion and exclusion were also used to blur the distinction between notions of nationality and gendered and sexualised identities. These activities within the overall event thus helped to construct quasified 'models' of the various national cultures' social orders (Handleman, 1998). 
Performative acts as spectacular entertainment were also central to constructing The Church experience. The organisation selected particular class-based performances in the strip acts, body mutilation 'blockhead' acts, coarse comedians and regurgitation acts. From an event dramaturgical perspective, these were further symbolic statements of antipodean identity and culture as dominantly working class and irreverent in its tastes, norms and practices. A managerial interpretation is that these acts, again, reinforced both the dramatic structuring of the experience and the moral script operating in its core proposition, while also perpetuating the floor-stage spatial relations. However, multiple forms of consumer 'co-creation' (Lugosi, 2007; 2008; 2009) were also evident in spectacular entertainment, including participating in games and exposing body parts for the audience's amusement.

Consumer co-creation was evident outside of the Church - people went to considerable effort to create costumes and to dress up. Moreover, co-creation continued inside the venue, partly through singing songs and drinking alcohol, but also through multiple forms of interaction. This included 'group-individual' interactions, for example, when groups of people collectively cheered or booed individuals during games and their other 'spectacular' performances on stage. It also included various forms of 'inter-individual' interactions, when people danced, talked, kissed, flirted and took photos of each other, alongside 'individualgroup' and 'inter-group' interactions as people cheered and booed other groups either alone or collectively.

Such forms of consumer co-creation reflect processes of identification (Hall, 1996; Bhabha, 1996) and entanglements of identity in the experience in several ways. First, there was evidence of 'experience socialisation' as consumers enacted mutuality by encouraging each other to make costumes, dress up and attend collectively. Experience socialisation here refers to individuals inspiring and instructing others to adopt certain behaviours (and attitudes) that are appropriate to the experiential context. Second, knowledge of music, lyrics and singing reflect sub-cultural competencies that already suggest identification with particular cultural values (Lugosi, 2008). These sub-cultural competencies are mobilised in and for the creation and consumption of a collective experience. Third, following from the previous points, the multiple forms of interaction tied individual performances of self (Goffman, 1990) to group experiences and thus to collective performances of selves. At times, these collective performances of self made direct references to national identities (e.g. during the roll call or competitions), but they also utilised associative references to broader identities and cultural values, including informality, working-class taste, masculinity, hetero-sexuality and sporting competition.

It is important to stress that identity performances among consumers were not always consistent or unified. This conceptualisation of venue operation, involving identity performances and practices, acknowledges that in any experiential context there are likely to be divergences between expected and thus permissible identity performances and actual identity performances. As demonstrated, in the case of The Church, women refusing to expose themselves despite pressure from operators and audience members, women disengaging during female strip artists' performances by leaving the room or turning their backs, customers engaging in behaviours outside acceptable norms (i.e., throwing liquids or cans, excessively rowdiness etc.), or even simply avoiding adopting fancy dress were acts of performative resistance. However, as noted above, the key issue here remains how operators and other consumers reacted to such resistance and attempted to compensate for it through 
orchestration and performative feedback that discouraged some behaviours while encouraging others.

\subsection{Representational practices}

Finally, representational practices refer both to visual and textual representations of the venue, the participants and the experience, and it is again possible to distinguish between organisational and consumer practices. As noted previously, within the venue the organisers filmed customers and projected images, with captions, for the amusement of other patrons. Again, this served to objectify individuals, their bodies and their embodied performances of self, turning them into consumables and mobilising their behaviours as humanic clues for fellow patrons. Consequently, visual representations of people within the venue also helped to shape people's performances of selves, for example, as they responded to encouragement to engage in particular behaviours, such as smiling, dancing or self exposure.

Representational practices continued beyond the context of the physical venue. Invoking notions of pilgrimage and making irreverent references to The Church as a symbolic inversion of the church on the organisation's website can be understood as attempts to represent and thus reconstruct The Church as a liminoid space (Turner, 1982). The organisation's website, and its social media pages, had a history of The Church and provided instructions to attendants. It also contained links to photo collections of The Church going back to the year 2000. In narrating The Church's history on the website, the organisers made direct reference to Australians and New Zealanders who formed the core audience at its outset. Such organisational representational practices thus also served to authenticate and distinguish this experiential setting by highlighting its historical roots (See Pine and Gilmore, 2008 for discussion of the importance of authenticity for differentiation and value creation). Furthermore, the description and images of the proceedings reinforced both the stability of The Church experience and the importance of the performative practices highlighted earlier. These representational practices were central to inducement because they socialised consumers, creating (and reinforcing) expectations for them regarding the experience and the embodied performances of self central to its construction.

Posting images, videos and commentary by consumers on social media sites were also important representational practices with symbolic as well as practical significance. These, too, reproduced place-images and place-myths (Shields, 1991) surrounding The Church, thus reflecting and inevitably shaping consumer experiences and informing inducement. More important, as other studies of online interaction show (e.g. Lugosi, et al., 2012; Watson et al., 2008), engaging in these representational practices also enabled social media users to articulate their identities and sense of identification. In this case, celebrating and sometimes even condemning the embodied consumption of The Church, enabled them to communicate their attitudes and values.

Finally, it is also useful to highlight other agents' representational practices, including journalists and cultural commentators (See e.g. Freeborn, 2008). Some of them may have received incentives to write about The Church. However, regardless of whether they were or not incentivised, they perpetuated the place-images and place-myths of The Church including direct references to antipodean history and consumers, alongside associative references to cultures and identities entangled in the consumer experience. 


\section{Conclusions and implications for management and research}

This paper contributes to knowledge in several ways. First, it provides detailed insight into an unexamined context, The Church, as both a hospitality/tourism operation and experience. Second, it provides a nuanced examination of the processes and practices involved in the operation of The Church, with particular reference to the ways in which notions of culture and identity were mobilised in the co-creation of experience. Third, and more broadly, it provides an alternative way to conceptualise and interrogate operations management, including how notions of culture and identity are entangled in experience creation. Each of these three themes is elaborated on below.

At the level of the specific research context, The Church was an extreme type of hospitality offering in which hedonistic forms of consumption and social organisation were closely tied to institutionalised processes of control. This paper has argued that The Church's existence can be conceptualised through the notion of inducement - the ongoing practices of mobilisation, involving spatial, material, performative and representational practices, which perpetuated the experiential possibilities of this space. It was argued that notions of identity were entangled in the production of The Church in multiple ways. Themes of commonality and collectivity were historically part of The Church's existence: they were the reasons for its establishment and continued to create symbolic focal points for its visitors. The paper has also argued that notions of identity, mobilised through multiple practices, were evident throughout The Church's operation. Stressing belonging, inclusion and exclusion through the roll call of nations, competitive games and ridicule mobilised particular expressions of identity or identification among its consumers. Moreover, through the celebration of hedonistic consumption and the objectification of women, notions of antipodean identities became blurred with particular articulations of class, gender and sexuality, which reproduced hetero-normative and hetero-patriarchal power relationships. Carnivalesque celebration of these similarities and differences in identity and identification thus helped to perpetuate the experiential model for this hospitality space.

Moving beyond the specific case, it is possible to argue that all hospitality operations involve entanglements of identity, and rely, in various degrees, on organisational-consumer cocreation in creating the experience. Consequently, the emerging themes from this study have a number of managerial implications and they also open up a several avenues of research. First, this study has shown the multiple ways in which identity is entangled in the experiential proposition and the actual experience. It is useful for operators to foreground questions of identity in designing and marketing their experiential propositions. In the case of The Church the core identity 'mooring' was antipodean-ness, which then emerged in multiple aspects of the experience (through the practices of mobilisation discussed above). However, the data in this study also suggested that direct references were only one part of the experience. It also pointed to several associative references, which can be linked, albeit indirectly, to conceptions of identity. Again, for operators designing and reviewing their experiential propositions, it is important to evaluate how associative references are entangled; and more specifically, how they can be mobilised as organisational resources.

Notions of shared cultural value and identity may be part of the overarching proposition for a particular hospitality or tourism experience, or it may be included in one or several part(s) of the broader experience. Moreover, people's relationship with the experience, which is directly linked to their potential for co-creation, may involve notions of identity through either: reinforcement, transformation through extension, transformation through contraction 
or contrast. For example, the experience, or part of the experience, may complement and thus reinforce existing notions of self. In the case of The Church, consuming and co-creating the experience may have reinforced existing notions of antipodean identity at least within the context of the experiential setting. The experience may offer opportunities to transform, through extension, notions of self. In the Church, the competitions and invocation of national difference through mocking references by the compère, for example, undoubtedly amplified notions of nationalistic pride during parts of the experience. However, experiences may also transform through contraction notions of self. Again, in the case of The Church, some consumers withdrew from certain articulations of antipodean-ness, e.g. in resisting pressures to perform actions (such as competitions, exhibitionism or sexual objectification) that were expected or normalised in that experiential setting. The experiential proposition may also stand in contrast to notions of self; although, disassociation may not stop people co-creating the experience. In the case of The Church, dissenting commentary on social media websites continues to perpetuate the place-image and place myths surrounding the experience. Consequently, examining in other contexts people's reactions to and relationships with the experiential propositions may offer a useful way to understand where and how their cocreation, as practice, would operate. Examining the different interactions of experience, cocreation and identity may also help to understand whether these had temporary, short-term or more fundamental, long-term changes in notions of identity and identification amongst consumers, thus influencing future attitudes and/or behaviours.

Second, this study has demonstrated how the construction of the experience relies on spatial, material, performative and representational practices of inducement in which various aspects of identity are entangled. Conceptualising hospitality venue operation as inducement, involving various practices of mobilisation, can help sensitise other operators and researchers seeking to deconstruct or interrogate other hospitality experiences. This offers a thematic framework for planning future hospitality operations and for evaluating how practices operate in existing hospitality contexts. Moreover, rather than adopting an organisation-centric view of experience creation and conceptualising it as a series of neatly functioning components in a service sequence (cf. Bitner et al., 2008), it conceptualises it as a dynamic processes in which multiple objects, actions and agencies interact. Practitioners and researchers drawing on this 'practices perspective' in their planning and evaluation of hospitality spaces can thus appreciate that a) experiences are always a set of organisational propositions, which operators may try to orchestrate, but cannot always guarantee, b) these propositions are only realised through co-creation, and, importantly, c) such propositions are only transformed into actual experiences through ongoing (spatial, material, representational and performative) practices of mobilisation.

This study had several limitations. First, this study did not attempt to focus on consumers' perspectives and the subjective experiences of The Church. Second, it did not incorporate frontline staff's perspectives on the experiential construction. Third, utilising a qualitative, inductive approach in a particular organisational setting makes generalisations problematic. However, it should be restated that the study was exploratory in nature and attempted to extrapolate from the case study (Patton, 2002) rather than test theory or particular hypotheses. Moreover, the notion of inducement and the proposition that future research can utilise the practices framework in conceptualising experiential contexts means the study's outcomes have potential 'transferability' (Lincoln \& Guba, 1985).

Future research can consider how consumers perceived and evaluated the experiential setting. Further qualitative studies, utilising participant observation, interviews and investigative 
internet research' (Lugosi et al., 2012), can examine consumers' broader subjective experiences before, during and after The Church. This can examine in particular their oral, textual and visual representational practices, both in person and through social media. Future studies could also consider in further detail the dynamics of their performative practices, including their motivations for investing in particular forms of co-creation e.g. making costumes, body modification, co-attendance, spectacular displays and interaction. Extending this, studies could examine how notions of self-concept, belonging and identification influenced their consumption or were, in turn, affected by consumption.

Qualitative approaches could also be utilised to capture frontline staff's perceptions of their overall experiential propositions, alongside their perceptions of the roles that they, their colleagues, consumers and other agents such as cultural commentators had in inducement and the (re)creation of the hospitality experience. Such research may consider frontline staff's perspectives on adopting particular spatial, material, performative and representational practices. It can also consider the risks, challenges and benefits associated with such practices, for example, in terms of human resources, operations management, marketing, licensing and legislations, ethics and revenue management.

Beyond the case study context, future research can attempt to evaluate the transferability of the thematic framework for conceptualising, planning and evaluating other types of experiential hospitality settings. Furthermore, if the themes raised in this study were adopted in future studies, researchers and practitioners can examine, through qualitative and quantitative research, the various marketing, operational and experiential functions that spatial, material, performative and representational practices may have in different organisational settings. Beyond assessing their functions, it would also be useful to examine the different impacts such practices have on consumer behaviour in the venue as well as beyond it in terms of satisfaction and future consumption decisions.

\section{References}

Adler, P.A., \& Adler, P. (1987). Membership roles in field settings. Newbury Park, CA: Sage.

Adler, P.A., \& Adler, P. (1998). Observational techniques. In N. Denzin, \& Y. Lincoln, (Eds.), Collecting and interpreting qualitative materials (pp. 79-109). Newbury Park, CA: Sage.

Agar, M. (1996). The professional stranger: An informal introduction to ethnography $\left(2^{\text {nd }}\right.$ ed.). San Diego: Academic Press.

Aitken, P. (1985). An observational study of young adults' drinking groups - II. Drink purchasing procedures, group pressures and alcohol consumption by companions as predictors of alcohol consumption. Alcohol and Alcoholism, 20(4), 445-457.

Althusser, L. (1984). Essays on ideology. London: Verso.

Andrews, H. (2005). Feeling at home: Embodying Britishness in a Spanish charter tourist resort. Tourist Studies, 5(3), 247-266.

Andrews, H. (2009). "Tits out for the boys and no back chat": Gendered space on holiday. Space and Culture, 12(2), 166-182. 
Atkinson, P., \& Hammersley, M. (2007). Ethnography: Principles in practice (3 ${ }^{\text {rd }}$ ed.). London: Routledge.

Barth, F. (Ed.). (1969). Ethnic groups and boundaries: The social organization of culture difference. Oslo: Norwegian University Press.

Beardsworth, A., \& Bryman, A. (1999). Late modernity and the dynamics of quasification: The case of the themed restaurant. The Sociological Review, 47(2), 228-257.

Bell, D., \& Valentine, G. (1997). Consuming geographies: We are where we eat. London: Routledge.

Berry, L.L., Wall, E.A., \& Carbone, L.P. (2006). Service clues and customer assessment of the service experience: Lessons from marketing. Academy of Management Perspectives, 20(2), 43-57.

Bhabha, H.K. (1990). Interview with Homi Bhabha: The third space. In J. Rutherford (Ed.), Identity: Community, culture, difference (pp. 207-221). London: Lawrence \& Wishart.

Bhabha, H.K. (1996). Culture's in-between. In S. Hall, \& P. du Gay (Eds.), Questions of cultural identity (pp. 53-60). London: Sage.

Bitner, M.J. (1992). Servicescapes: The impact of physical surroundings on customers and employees. Journal of Marketing, 56(2), 57-71.

Bitner, M.J., Ostrom, A., \& Morgan, F. (2008). Service blueprinting: A practical technique for service innovation. California Management Review, 50(3), 66-94.

Blumer, H. (1954). What is wrong with social theory. American Sociological Review, 18, 310.

Bowman, G. (1989). Fucking tourists: Sexual relations in Jerusalem's old city. Critique of Anthropology, 9(2), 77-93.

Braun, V., \& Clarke, V. (2006). Using thematic analysis in psychology. Qualitative Research in Psychology, 3, 77-101.

Brown, S., \& Patterson, A. (2000). Knick-knack paddy-whack, give a pub a theme. Journal of Marketing Management, 16(6), 647-662.

Burkitt, I. (1999). Bodies of thought: Embodiment, identity and modernity. London: Sage.

Butler, J. (1999). Gender trouble: Feminism and the subversion of identity. London: Routledge.

Carbone, L., \& Haeckel, S. (1994). Engineering customer experiences. Marketing Management, 3(3), 9-19. 
Chathoth, P., Altinay, L., Harrington, R.J., Okumus, F., \& Chan, E.S.W. (2013). Coproduction versus co-creation: A process based continuum in the hotel service context. International Journal of Hospitality Management, 32, 11-20.

Clarke, I., Kell, I., Schmidt, R., \& Vignali, C. (1998). Thinking the thoughts they do: Symbolism and meaning in the consumer experience of the "British pub". Qualitative Market Research: An International Journal, 1(3), 132-144.

Countryman, G.C., \& Jang, S. (2006). The effects of atmospheric elements on customer impressions: The case of hotel lobbies. International Journal of Contemporary Hospitality Management, 18(7), 534-545.

Crawford, R. (2009). A commercial identity? The antipodean image in London. In J. Fernandez (Ed.), Diasporas: Critical and inter-disciplinary perspectives (pp. 295-304). Oxford: Inter-disciplinary Press.

Cuthill, V. (2007). Sensing and performing hospitalities and socialities of tourist places: Eating and drinking out in Harrogate and Whitehaven. In J. Germann Molz, \& S. Gibson (Eds.), Mobilizing hospitality (pp. 83-100). Aldershot: Ashgate.

Denzin, N. (2009). The research act. New Brunswick, NJ: Aldine Transaction.

Fiske, J., Hodge, B., \& Turner, G. (1987). Myths of Oz: Reading popular culture. Winchester, MA: Allen and Unwin.

Forsyth, A.J.M., \& Coonan, M. (2008). Alco-pop? The use of popular music in Glasgow pubs. Popular music and Society, 31(1), 57-78.

Freeborn, A. (2008). Church born again. Camden guide. http://www.camdenguide.co.uk/news/church.htm. Accessed 04.01.12.

Freedman, J. L., \& Perlick, D. (1979). Crowding, contagion, and laughter. Journal of Experimental Social Psychology, 15(3), 295-303.

Guéguen, N., Jacob, C., Le Guellec, H., Morineau, T., \& Lourel, M. (2008). Sound level of environmental music and drinking behavior: A field experiment with beer drinkers. Alcoholism: Clinical and Experimental Research, 32, 1795-1798.

Guillemin, M., \& Drew, S. (2010). Questions of process in participant-generated visual methodologies. Visual Studies, 25(2), 175-188.

Goffman, E. (1990). The presentation of self in everyday life. London: Penguin.

Gibbs, D., \& Ritchie, C. (2010). Theatre in restaurants: Constructing the experience. In M. Morgan, P. Lugosi, \& J.R.B. Ritchie (Eds.), The tourism and leisure experience: Consumer and managerial perspectives (pp. 181-201). Bristol: Chanel View.

Gillespie, C., \& Morrison, A. (2001). Elite hotels: Painting a self-portrait. International Journal of Tourism Research, 3(2), 115-121. 
Gilmore, J.H., \& Pine, J. (2002). Differentiating hospitality operations via experiences: Why selling services is not enough. Cornell Hotel and Restaurant Administration Quarterly, 43(3), 87-96.

Grayson, R. A.S., \& McNeill, L. S. (2009). Using atmospheric elements in service retailing: Understanding the bar environment. Journal of Services Marketing, 23(7), 517-527.

Greiner, A.L. (2001). Popular culture, place images, and myths: The promotion of Australia on American television. Journal of Popular Culture, 34(4), 91-101.

Hall, S. (1996). Introduction: Who needs identity? In S. Hall, \& P. du Gay (Eds.), Questions of cultural identity (pp. 1-17). London: Sage.

Hall, S., \& du Gay, P. (Eds.). (1996). Questions of cultural identity. London: Sage.

Handelman, D. (1998). Models and mirrors: Towards an anthropology of public events. New York: Berghahn.

Hanefors, M., \& Mossberg, L. (2003). Searching for the extraordinary meal experience. Journal of Business and Management, 9(3), 249-270.

Hemmington, N. (2007). From service to experience: Understanding and defining the hospitality business. The Service Industries Journal, 27(6), 747-755.

Hoffman, K., \& Turley, L. (2002). Atmospherics, service encounters and consumer decision making: An integrative perspective. Journal of Marketing Theory and Practice, 10(3), 33-47.

Hosfetede, G., Hofstede , G.J., \& Minkov, M. (2010). Cultures and organizations ( $3^{\text {rd }}$ ed.). New York: McGraw-Hill.

Jacob, C. (2006). Styles of background music and consumption in a bar: An empirical evaluation. International Journal of Hospitality Management, 25(4), 716-720.

Jenkins, R. (2004). Social identity ( $2^{\text {nd }}$ ed.). London: Routledge.

Kelen, C. (2003). Anthems of Australia: Singing complicity. National Identities, 5(2), 161177.

Latour, B. (2005). Reassembling the social: An introduction to actor-network-theory. Oxford University Press: Oxford/New York.

Lee, R.M. (2000). Unobtrusive methods in social research. Buckingham: Open University Press.

Lefebvre, H. (1991). The production of space. Oxford: Blackwell.

Lego, C., Wood, N., McFee, S., \& Solomon, M. (2002). A thirst for the real thing in themed environments: Consuming authenticity in Irish pubs. Journal of Foodservice Business Research, 5(2), 61-74. 
Limb, M., \& Dwyer, C. (Eds.). (2001). Qualitative methodologies for geographers: Issues and debates. London: Arnold.

Lin, I.Y. (2004). Evaluating a servicescape: The effect of cognition and emotion. International Journal of Hospitality Management, 23(2), 163-178.

Lin, I.Y. (2010). The combined effect of color and music on customer satisfaction in hotel bars. Journal of Hospitality Marketing and Management, 19(1), 22-37.

Lincoln, Y. S., \& Guba, E. G. (1985). Naturalistic inquiry. Beverly Hills, CA: Sage.

Lofland, J. (2006). Analyzing social settings: A guide to qualitative observation and analysis ( $4^{\text {th }}$ ed.). Belmont, CA: Wadsworth.

Lugosi, P. (2006). Between overt and covert research: Concealment and disclosure in and ethnographic study of commercial hospitality. Qualitative Inquiry, 12(3), 541-561.

Lugosi, P. (2007). Consumer participation in commercial hospitality. International Journal of Culture, Tourism and Hospitality Research, 1(3), 227-236.

Lugosi, P. (2008). Hospitality spaces, hospitable moments: Consumer encounters and affective experiences in commercial settings. Journal of Foodservice, 19(2), 139-149.

Lugosi, P. (2009). The production of hospitable space: Commercial propositions and consumer co-creation in a bar operation. Space and Culture, 12(4), 396-411.

Lugosi, P., \& Erdélyi, P. (2009). From marketing to market practices: Assembling the ruin bars of Budapest. In A. Fyall, M. Kozak, L. Andreu, J. Gnoth, \& S. S. Lebe (Eds.), Marketing innovations for sustainable destinations: Operations, interactions, experiences. (pp. 299310). Oxford: Goodfellows Publishers.

Lugosi, P., Janta, H., \& Watson, P. (2012). Investigative management and consumer research on the internet. International Journal of Contemporary Hospitality Management, 24(6), 838854.

Lusch, R.F., \& Vargo, S.L. (2006). Service-dominant logic: Reactions, reflections and refinements. Marketing Theory, 6(3), 281-288.

Lynch, P., Germann Molz, J., McIntosh, A., Lugosi, P., \& Lashley, C. (2011). Theorising hospitality. Hospitality and Society, 1(1), 3-24.

Machleit, K.A., Eroglu, S.A., \& Mantel, S.P. (2000). Perceived retail crowding and shopping satisfaction: What modifies this relationship? Journal of Consumer Psychology, 9(1), 29-42.

Mewett, P. (1999). Fragments of a composite identity: Aspects of Australian nationalism in a sports setting. The Australian Journal of Anthropology, 10(3), 357-375.

Milliman, R.E. (1986). The influence of background music on the behavior of restaurant patrons. Journal of Consumer Research, 13, 286-289. 
Morgan, M., Watson, P., \& Hemmington, N. (2008). Drama in the dining room: Theatrical perspectives on the foodservice encounter. Journal of Foodservice, 19(2), 111-118.

Morgan, M., Lugosi, P., \& Ritchie, J.R.B. (Eds.). (2010). The tourism and leisure experience: Consumer and managerial perspectives. Bristol: Channel View.

Muñoz, C.L., \& Wood, N.T. (2009). A recipe for success: Understanding regional perceptions of authenticity in themed restaurants. International Journal of Culture, Tourism and Hospitality Research, 3(3), 269-280.

Muñoz, C.L., Wood, N.T., \& Solomon, M.R. (2006). Real or blarney? A cross-cultural investigation of the perceived authenticity of Irish pubs. Journal of Consumer Behaviour, $5(3), 222-234$.

O’Mahony, G.B., Hall, J., \& Binney, J. (2006). A situational model of development in hospitality retailing: The case of Irish pubs. Journal of Services Research, 5(2), 77-95.

Patton, M.Q. (2002). Qualitative research and evaluation methods (3rd ed.). London: Sage.

Phillips, T., \& Smith, P. (2000). What is 'Australian'? Knowledge and attitudes among a gallery of contemporary Australians. Australian Journal of Political Science, 35(2), 203-224.

Pine, B.J., \& Gilmore, J.H. (1999). The experience economy. Boston: Harvard Business School Press.

Pine J.P., \& Gilmore, J.H. (2008). The eight principles of strategic authenticity. Strategy and Leadership, 36(3), 35-40.

Prahalad, C.K., \& Ramaswamy, V. (2004). Co-creation experiences: The next practice in value creation. Journal of Interactive Marketing, 18(3), 5-14.

Purdie, N., \& Craven, R. (2006). Young people's perceptions of what it means to be an Australian. http://research.acer.edu.au/learning_processes/1. Accessed 12.06.12

Quan, S., \& Wang, N. (2004). Towards a structural model of the tourist experience: An illustration from food experiences in tourism. Tourism Management, 25(3), 297-305.

Robinson, S. (2011). Inventing Australia for Americans: The rise of the Outback Steakhouse restaurant chain in the USA. Journal of Popular Culture, 44(3), 545-562.

Rojek, C. (1997). Indexing, dragging and the social construction of tourist sights. In C. Rojek, \& J. Urry, J. (Eds.), Touring cultures: Transformations of travel and theory (pp. 5274). London: Routledge.

Selwyn, T. (2000). An anthropology of hospitality. In C. Lashley, \& A. Morrison (Eds.), In search of hospitality: Theoretical perspectives and debates (pp. 18-37). Oxford: ButterworthHeinemann. 
Shaw, G., Bailey, A., \& Williams, A. (2011). Aspects of service-dominant logic and its implications for tourism management: Examples from the hotel industry. Tourism Management, 32, 207-214.

Shields, R. (1991). Places on the margin: Alternative geographies of modernity. London: Routledge.

Strauss, A., \& Corbin, J. (1998). The basics of qualitative research: Techniques and procedures for developing grounded theory $\left(2^{\text {nd }}\right.$ ed.). Thousand Oak, CA: Sage.

The Church (2008). In the beginning. http://www.thechurch.co.uk/in_the_beginning. Accessed 12.04.2008.

The Church (2012). About us. http://www.thechurchlondon.com/about_us. Accessed 04.01.2012.

Thurnell-Read, T. (2011). 'Common-sense' research: Senses, emotions and embodiment in researching stag tourism in Eastern Europe. Methodological Innovations Online, 6(3), 39-49.

Tombs, A., \& McColl-Kennedy, J.R. (2003). Social-servicescape conceptual model. Marketing Theory, 3(4), 447-475.

Turner, V. (1982). From ritual to theatre: The human seriousness of play. New York: PAJ Publications.

Van der Duim, V. R., Ren, C., \& Jóhannesson, G. T. (2013). Ordering, materiality and multiplicity: Enacting ANT in tourism. Tourist Studies, 13(1), 3-20.

Vargo, S.L., Maglio, P.P., \& Akaka, M.A. (2008). On value and value co-creation: A service systems and service logic perspective. European Management Journal, 26(3), 145-152.

Walls, A.R., Okumus, F., Wang, Y., \& Kwun, D.J. (2011a). An epistemological view of consumer experiences. International Journal of Hospitality Management, 30(1), 10-21.

Walls, A., Okumus, F., Wang, Y.C., \& Kwun, D.J. (2011b). Understanding the consumer experience: An exploratory study of luxury hotels. Journal of Hospitality Marketing and Management, 22(2), 166-197.

Watson, P., Morgan, M., \& Hemmington, N. (2008). Online communities and the sharing of extraordinary restaurant experiences. Journal of Foodservice, 19(6), 289-302.

Weed, M. (2006). The story of an ethnography: The experience of watching the 2002 World Cup in the pub. Soccer and Society, 7(1), 76-95.

West, B. (2006). Consuming national themed environments abroad: Australian working holidaymakers and symbolic national identity in 'Aussie' theme pubs. Tourist Studies, 6(2), 139-155.

Wilson, T.M. (Ed.). (2005). Drinking cultures: Alcohol and identity. Oxford: Berg. 
Zhang, J., Beatty, S.E., \& Mothersbaugh, D. (2010). A CIT investigation of other customers' influence in services. Journal of Services Marketing, 24(5), 389-399.

Ziakas, V., \& Costa, C. A. (2012). 'The show must go on': Event dramaturgy as consolidation of community. Journal of Policy Research in Tourism, Leisure and Events, $4(1), 28-47$

Zomerdijk, L.G., \& Voss, C.A. (2010). Service design for experience-centric services. Journal of Service Research, 13(1), 67-82. 